\title{
Review on Precast Beam Column Joint
}

\author{
Shilpa $\mathrm{S}^{1} \mid$ Dr. GopinathNayak ${ }^{2}$ | Dr. Ramakrishna Hegde ${ }^{3}$ \\ ${ }^{1}$ Department of Civil Engineering, Srinivas University College of Engineering and Technology, Mangalore, Karnataka, \\ India. \\ ${ }^{2}$ Department of Civil Engineering, Manipal Institute of Technology, Manipal, Karnataka, India. \\ ${ }^{3}$ Department of Civil Engineering, Srinivas University College of Engineering and Technology, Mangalore, Karnataka, \\ India.
}

\section{To Cite this Article}

Shilpa S., Dr. GopinathNayak \& Dr. Ramakrishna Hegde. Review on Precast Beam Column Joint. International Journal for Modern Trends in Science and Technology 7, 81-83 (2021).

\section{Article Info}

Received on 11-April-2021, Revised on 28-April-2021, Accepted on 06-May-2021, Published on 12-May-2021.

\section{ABSTRACT}

Building projects purvey many advantages by the use of precast concrete frame structures in expeditious construction, lowering formwork, upgrade construction condition, carbon emission depletion and environmental conservation. The behavior of precast concrete structures are subjected to different loading conditions. Loading conditions depend on type, location and the connections between elements. Exiguous strength and indigent ductility of the beam column joint create the weakest link in the structure, which the reason for failure of any kind of structures. So various literature have been reviewed to ensure the reliable connections between the beam column joints.

KEYWORDS: Precast, beam column joint, loading, review.

\section{INTRODUCTION}

Precast concrete (PCC) systems allow the fast and effective completion of various buildings and its popularity is increasing because of its better quality control, reducing material wastage and quick in construction. Joints are weakest element in precast construction. The structural components are joined together mechanically, using connections such as bolts, welds, anchors, reinforcing steel, and grout and concrete in the joints. Structural components connections must fortify the structural integrity of the entire structure. The aim of such structural connections is to transfer forces between elements to accredit the required structural interaction when the system is loaded. Load distribution in the beam-column joints of PCC members and its behavior has been studied by researchers. The combination of the connection affects the constructability, stability, strength, flexibility, and residual forces in the structure. However, the connections of PCC members are generally designed for different loading conditions. The advancement of connections for different loading conditions has enabled the researchers to evaluate and produce precise connections.

\section{LITERATURE REVIEW}

(Wang, Barbagallo, \& Pan, 2020) After an earthquake high resilience capacity buildings are required for quick recovery of building functionality. Reinforced concrete (RC) frame structures are designed to endure seismic actions by means of plastic deformation of the structural components, which may lead to large residual deformation. Because of this, the slab exerts a strengthening effect on the beams, which increases the bending resistance of the beams but pro motes an unfavourable and undesired strong-beam-weak-column damage mechanism in 
the structure. Conventional RC slabs usually suffer from severe damage due to earthquakes.

(Li, Qi, \&Teng, 2020) In this study, a novel prefabricated beam-to-column steel joint suitable for precast concrete structures was developed. The proposed steel joint with dampers could replace cast-in-situ concrete beam-to-column joints in precast concrete structures.

(Z. Y. Zhang, Ding, Nie, \& Fan, 2020) In traditional precast reinforced concrete $(\mathrm{RC})$ frame structures, the reinforcement details are usually complex in the joint zone, which makes the fabrication process difficult and thus affects the construction quality and speed. Ultra-high performance concrete (UHPC) exhibits substantially higher shear resistance and bond strength than normal concrete due to its much larger compressive and tensile strengths. As a result, the application of UHPC can significantly help reducing the amount of stirrups and anchorage length of the longitudinal bar in the joint zone of precast $\mathrm{RC}$ frames, which can obviously simplify the joint construction. In this study, four large-scale interior beam-column joints were fabricated and tested cyclically.

(Vidjeapriya, Bahurudeen, \& Jaya, 2013)

In this study a 3-D nonlinear FE model was developed to study the response of an exterior precast beam to column connection subjected to reverse cyclic loading. Tests of a one-third scale exterior beam column precast concrete connections was conducted. Two types of connections were compared. The connections included a monolithic connection and two precast beam - column connections (i) using J-bolt (ii) using Cleat Angle

(Y. Liu, Guo, Ding, Wang, \& Liu, 2020)

An assembled concrete structure is a highly efficient structural form for industrial buildings. It has been widely used owing to its advantages such as convenient construction, energy saving, and environmental protection. The connection mode is key for improving the construction efficiency of assembled concrete frame structures; furthermore, it is an important feature that distinguishes an assembled concrete structure from a cast-in-place concrete structure. The anti-seismic capacity of an assembled concrete structure system primarily depends on the connection form.
(Benayoune, 2008) Precast Concrete Sandwich Panels (PCSP) generally span vertically between foundations and floors or roofs to provide an insulated outer shell to buildings carrying mostly axial loads. PCSP with shear truss connectors is typically fabricated of two concrete Wythe's tied together with truss-shaped shear connectors equally spaced along the length of the panel. Depending on the degree of composite action achieved, a PCSP may be regarded as fully composite, semi-composite or non-composite panel. The current paper aims to experimentally and theoretically investigate the structural behavior of the PCSP under flexure and examines the effectiveness of the truss shear connectors and its role in ensuring composite behavior.

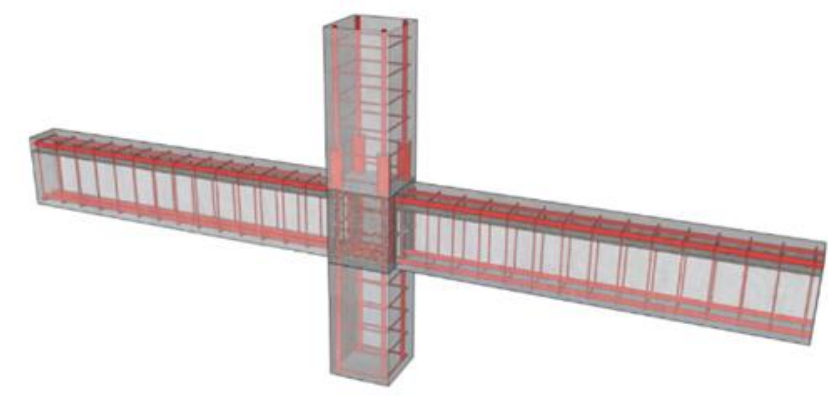

Figure 1: Beam column joint

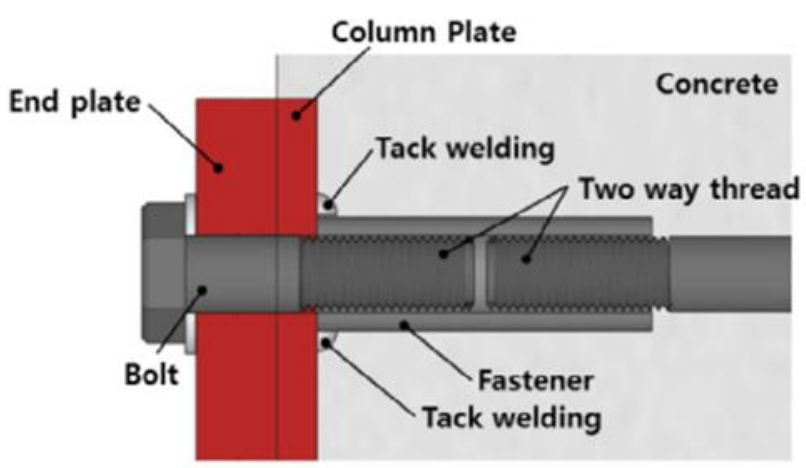

Figure 2: Mechanical joint

\section{CONCLUSION}

Conclusions drawn from the literature review:

1. Beam column connections, various experiments are carried out and are validated with FEA softwares

2. Experiments are conducted by varying materials in concrete to enhance its properties of precast structural elements

3. Loading tests were conducted on the joints to study its behaviour on different loading condition. 


\section{REFERENCES}

[1] Benayoune, A. (2008). Flexural behaviour of pre-cast concrete sandwich composite panel - Experimental and theoretical investigations. Construction and Building Materials, 22, 580-592.

[2] Li, Z., Qi, Y., \& Teng, J. (2020). Experimental investigation of prefabricated beam-to-column steel joints for precast concrete structures under cyclic loading. Engineering Structures, 209, 110217.

[3] Liu, J., Xue, Y., Wang, C., Nie, J., \& Wu, Z. (2020). Experimental investigation on seismic performance of mechanical joints with bolted flange plate for precast concrete column. Engineering Structures, 216, 110729.

[4] Liu, Y., Guo, Z., Ding, J., Wang, X., \& Liu, Y. (2020). Experimental study on seismic behaviour of plug-in assembly concrete beam-column connections. Engineering Structures, 221, 111049.

[5] Nilforoush, R., Nilsson, M., \&Elfgren, L. (2017). Experimental evaluation of tensile behaviour of single cast-in-place anchor bolts in plain and steel fibre-reinforced normal- and high-strength concrete. Engineering Structures, 147, 195-206.

[6] Vidjeapriya, R., Bahurudeen, A., \& Jaya, K. P. (2013). Nonlinear analysis of exterior precast beam-column J-Bolt and cleat angle connections. INTERNATIONAL JOURNAL OF CIVIL AND STRUCTURAL ENGINEERING, 4, 87-97.

[7] Wang, H., Barbagallo, F., \& Pan, P. (2020). Test of precast pre-stressed beam-to-column joint with damage-free reinforced concrete slab. Engineering Structures, 210, 110368.

[8] Zhang, J., Ding, C., Rong, X., Yang, H., \& Li, Y. (2020). Development and experimental investigation of hybrid precast concrete beam-column joints. Engineering Structures, 219, 110922.

[9] Zhang, Z. Y., Ding, R., Nie, X., \& Fan, J. S. (2020). Seismic performance of a novel interior precast concrete beam-column joint using ultra-high performance concrete. Engineering Structures, 222, 111145.
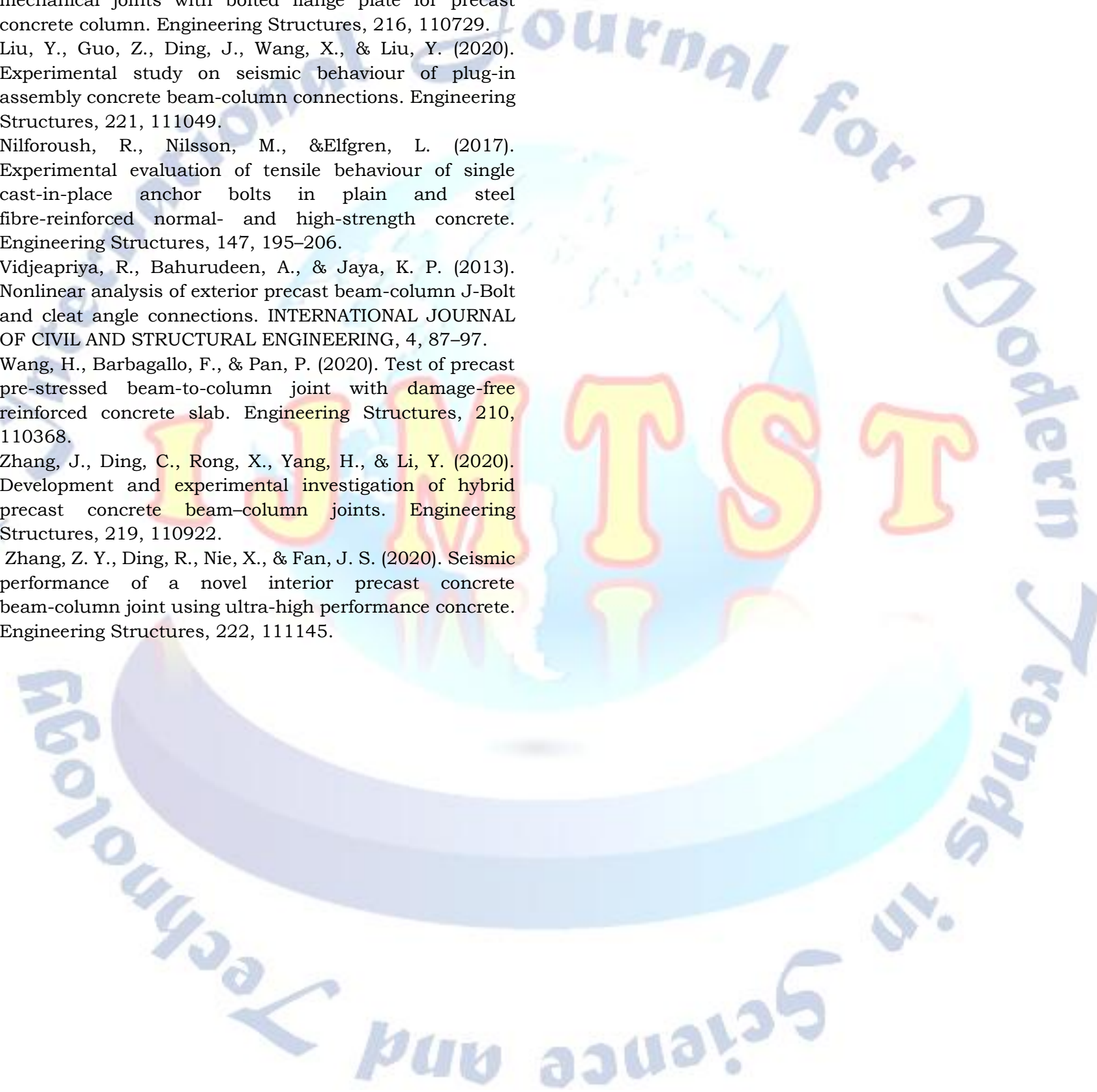